\title{
Electric Energy Management Modeling for Kingdom of
}

\section{Bahrain}

\author{
Isa Salman Qamber ${ }^{1}$, Mohammed Yusuf Al-Hamad ${ }^{2}$ and Abdul Majeed Habib Abdul Karim ${ }^{3}$ \\ 1. Department of Electrical \& Electronics Engineering, University of Bahrain, Isa Town 33831, Kingdom of Bahrain \\ 2. Client Interface Executive, Operations Directorate-Trade Section, GCC Interconnection Authority, Dammam 31481, Kingdom of \\ Saudi Arabia
}

3. Office of Minister of Energy, Electricity \& Water Authority, Manama 2, Kingdom of Bahrain

Received: July 20, 2015 / Accepted: September 01, 2015 / Published: October 31, 2015.

\begin{abstract}
In the deregulated economy, the maximum load forecasting is important for the electric industry. Many applications are included such as the energy generation and purchasing. The aim of the present study is to find the most suitable models for the peak load of the Kingdom of Bahrain. Many mathematical methods have been developing for maximum load forecasting. In the present paper, the modeling of the maximum load, population and GDP (gross domestic product) versus years obtained. The curve fitting technique used to find that models, where Graph 4.4.2 as a tool used to find the models. As well, Neuro-Fuzzy used to find the three models. Therefore, three techniques are used. These three are exponential, linear modeling and Neuro-Fuzzy. It is found that, the Neuro-Fuzzy is the most suitable and realistic one. Then, the linear modeling is the next suitable one.
\end{abstract}

Key words: Neuro-Fuzzy, peak loads, population, GDP, Graph 4.4.2, curve fitting.

\section{Introduction}

As it is well known, the load forecasts divided into three categories. These types are the short-term forecasts are for a period of one hour to one week, medium forecasts for period of a week to a year, and the third type is the long-term forecasts, which are longer than a year. Most load forecast methods use statistical techniques or artificial intelligence algorithms such as neural networks, fuzzy logic and expert systems.

Load forecasting helps an electric utility in making important decisions including as mentioned earlier such as decisions on purchasing and generating electric power. Also, more decisions are load switching, area planning and development. Demand for electric power typically depends on several conditions such as GDP (gross domestic product) and

Corresponding author: Isa Salman Qamber, Ph.D., professor, research field: electric power systems reliability. E-mail: iqamber@uob.edu.bh. the population. These factors are taken into consideration to estimate the maximum load for Kingdom of Bahrain on the long term.

In the present paper, the maximum annual loads for Kingdom of Bahrain for the years 2003-2014 which means twelve years are considered. Based on these annual loads, the model is made using the curve fitting technique through using the package Graph 4.4.2. Using this package, a number of models are made. Graph 4.4.2 is a program designed to draw graphs of mathematical functions in a coordinate system and similar things. It is a standard Windows program with menus and dialogs. At the same time, it is capable of drawing standard functions, parametric functions, polar functions, tangents, point series, shadings and relations. It is also possible to evaluate a function for a given point, trace a graph. Graph 4.4.2 is an open source application used to draw mathematical graphs in a coordinate system.

Qader, et al. [1] in their paper, present study 
considering maximum electric load of Kingdom of Bahrain over a period of five years. Monte Carlo method used, where its basic variables are presented and discussed from the standard deviation and reserve point of view. The results compared on a weekly and yearly basis. Almeshaiei, et al. [2] in their study, a pragmatic methodology was used as a guide to construct electric power load forecasting models. The methodology they used based on decomposition and segmentation of the load time series. In their study, real data for Kuwait were used. Finally, they obtained the results, which helped in getting the forecast load for future. Qamber [3] in his study, derived a number of models to estimate the electrical demand for future load in Kingdom of Bahrain. The models derived in away describing the electric power demand during summer period. Tawalbeh, et al. [4] in their study, presented a nonlinear method to estimate the consumed energy in distribution feeders. The proposed procedure uses the statistical solution algorithm to analyze the active energy monthly consumption, which enables one to estimate the energy consumption during any period of the year. The effective of the proposed method is demonstrated by comparing the simulated results with that of real measured data. Qamber [5] in his study, proposes the impact of the air temperature on electricity demand as expected. The study concentrated on the period through the years 2009 until 2012. The results obtained using the curve fitting technique. In the study, it is concentrated on the lower, average and maximum loads. Three scenarios carried out and their models obtained. Ryu, et al. [6] in their study, which carried out on the base of Super Grade Hotels that have high-energy consumption per unit area cause a massive amount of load. The study is concentrated on analyzing the energy consumption by using electricity load data. The study carried out to reduce the amount of electricity and peak load through the management and energy efficiency improvement of the large hotels. Koo, et al. [7] in their study performed short-term electric load forecasting using three methods and compared each result. The authors used K-means and k-NN (k-nearest neighbors algorithm) to eliminate error from calendar based classification before making a forecasting model. The authors compared three methods such as artificial neural networks, SES (simple exponential smoothing) and GMDH (group method of data handling). Upshaw, et al. [8] in their article discuss the development of a model for evaluating peak load reduction and change in overall energy consumption for a residential air conditioning compressor with and without condenser-side thermal storage. The model used simulated cooling load data for a typical home in Austin (Texas) based on summer 2011. System performance varied depending on weather data. Kot, et al. in their paper [9] review maximum power point tracking algorithms dedicated for small wind turbines. Three algorithms used are discussed. Two of them are based on turbine static parameters, where the third one iteratively searches for optimum operating point and it does not require prior knowledge of the turbine. Barzin, et al. [10] in their article, present an analysis of a price-based control system in conjunction with energy storage using phase change materials for two applications. Their results showed the importance of selecting a suitable price constraint to examine the benefits.

\section{Annual Peak Load Demand}

The available historical data for the period 2003 until the year 2014 helped the present study to carried out for estimated values. The factors mentioned in the previous section used to form the models, which help to estimate the annual maximum load for Kingdom of Bahrain. These factors summarized as follows:

- the population;

- the GDP;

- the years (time).

The first two factors depend on the behavior of the human. These factors vary from country to country. Back again to the third factor, this factor depends on 
the load itself. The last factor depends on the power system of the Kingdom of Bahrain.

By collecting and analyzing more electric load demand information, this will help the improvement the knowledge of loads in electric power systems.

The load modeling and forecasting based on several factors influencing the load demand. Some factors are:

- time factors: time of the day, day of the week and time of the year;

- climate factors: temperature, humidity, etc.;

- previous load values;

- load curve patters.

The power trading and the EEM (electrical energy management) topics introduced in Kingdom of Bahrain, because it reached a specific concern due to its contribution to economic development and environmental advancement. The power trading and EEM have a logical outcome and the planning of varieties of initiatives that deployed to reduce energy and fuel consumptions. Power trading can be used to reduce the cost of the unit energy which used by the consumer and run the system base on the economic reason.

The EEM is used when there is a growing demand where the demand load expected to be more than the generation, also it is used when there is a shortage in resources "fuel, finance, or energy". EEM can be used on the demand side to reduce the cost of purchasing electric energy.

There are several types of load management techniques [11]. The EEM will be used in the planning and implementing of the power trading activities to supply peak load demand. The objective of EEM is to influence Bahrain to pre-plan their electricity generation in consideration to achieve peak demand in most economical basis. A typical load curve for typical electricity grid is shown in Fig. 1.

\section{Annual Peak Load Modeling}

While it is important to determine the estimated peak load based on the actual values for Kingdom of

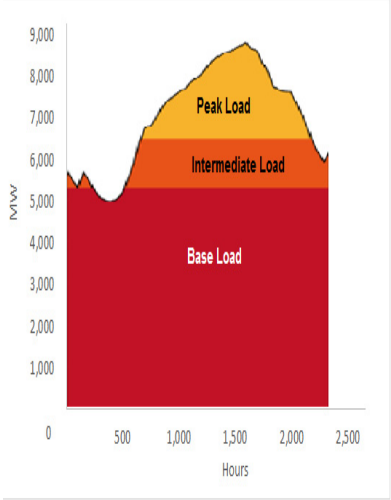

High summer demand day

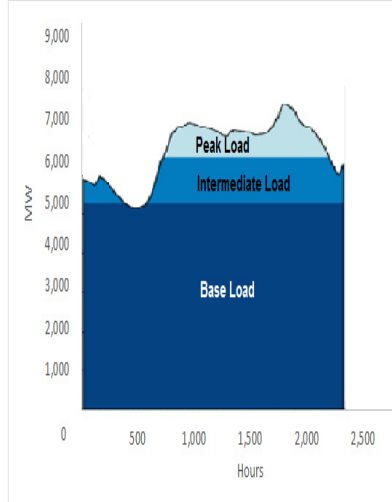

High winter demand day
Fig. 1 Load curves for typical electricity grid.

Bahrain through the years 2003 till 2014, it is necessarily to find the suitable technique for that purpose which is Graph 4.4.2. The technique helps to find the most suitable model for the available peak load data. The obtained estimated values through the period 2003 till 2025.

Eq. (1) illustrates the variation of maximum load demand model (exponential model) for Kingdom of Bahrain through the years (2003-2014). The results coming out of the derived estimated peak load values equation for the period 2003-2025 are shown in the present article. The results are illustrated in Fig. 2 and listed in Table 1. The same data modeled as a linear model, where Eq. (2) represents the growth variation of maximum load and estimated that load for the period 2003-2025 using the linear model. These results are illustrated in Fig. 3 and listed in Table 2.

$$
\text { maximum estimated load }(x)=
$$

$$
\left(5.7382629 \times 10^{-57}\right) \times(1.0707155)^{x}
$$

maximum estimated load $(x)=$

$$
(154.2028 x)-307,365.15
$$

where:

maximum estimated load $(x)$ : the maximum estimated load as a function of year $(x)$ :

$$
x \text { : the year. }
$$

In the present paper, the model created tested for with actual data available to examine the model and find wither its forecasted values are acceptable or not. After that, the model will be used to forecast the 


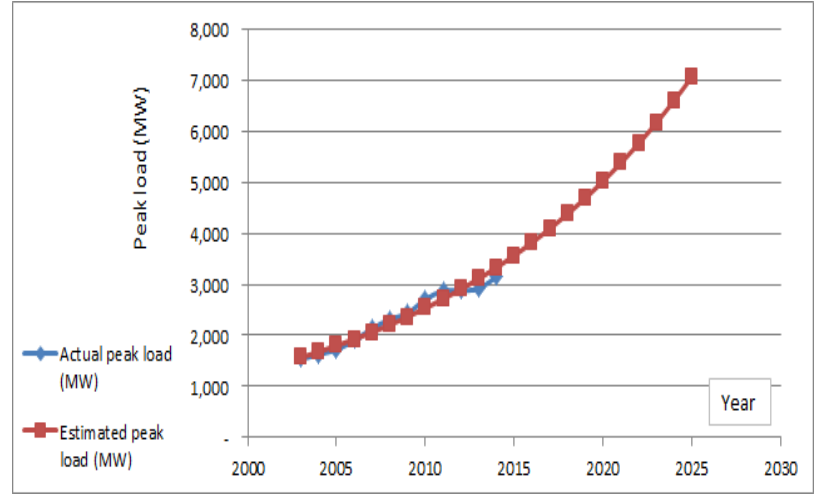

Fig. 2 Actual and estimated maximum load for Kingdom of Bahrain using exponential model.

Table 1 Actual and estimated peal load using exponential modeling.

\begin{tabular}{lll}
\hline Year & $\begin{array}{l}\text { Actual peak load } \\
\text { (MW) }\end{array}$ & $\begin{array}{l}\text { Estimated peak load } \\
\text { (MW) }\end{array}$ \\
\hline 2003 & 1,535 & 1,570 \\
2004 & 1,632 & 1,681 \\
2005 & 1,725 & 1,800 \\
2006 & 1,906 & 1,928 \\
2007 & 2,136 & 2,064 \\
2008 & 2,314 & 2,210 \\
2009 & 2,438 & 2,366 \\
2010 & 2,708 & 2,533 \\
2011 & 2,871 & 2,713 \\
2012 & 2,880 & 2,904 \\
2013 & 2,917 & 3,110 \\
2014 & 3,152 & 3,330 \\
2015 & & 3,565 \\
2016 & & 3,817 \\
2017 & & 4,087 \\
2018 & & 4,376 \\
2019 & & 4,686 \\
2020 & & 5,017 \\
2021 & & 5,372 \\
2022 & & 5,752 \\
2023 & & 6,158 \\
2024 & & 6,594 \\
2025 & & 7,060 \\
\hline
\end{tabular}

maximum power for the next ten years. Expected error for the forecasted period is the same error percentage found for the previous period. This paper presents acceptable predicators result values. It is clear that, the model in the present paper was used to predict the peak load for two periods. The first period is the actual peak load period (2003-2014), while the second period is the estimated peak load period (2015-2025).

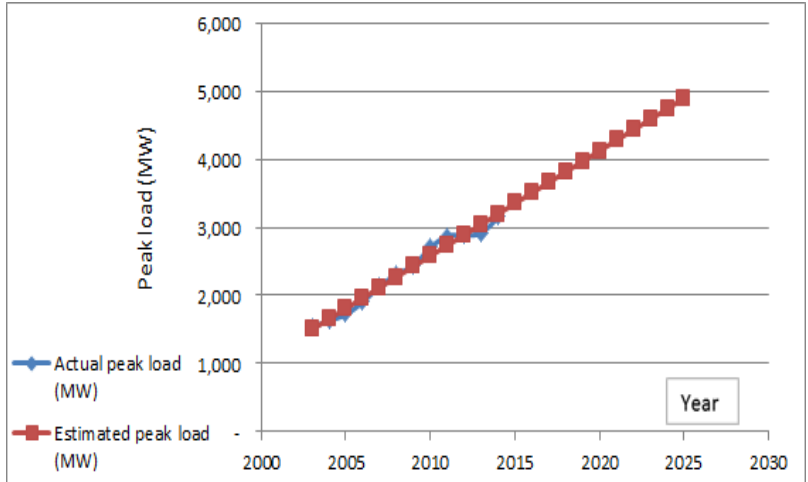

Fig. 3 Actual and estimated maximum load for Kingdom of Bahrain using linear model.

Table 2 Actual and estimated peak load using linear modeling.

\begin{tabular}{lll}
\hline Year & $\begin{array}{l}\text { Actual peak load } \\
\text { (MW) }\end{array}$ & $\begin{array}{l}\text { Estimated peak load } \\
(\mathrm{MW})\end{array}$ \\
\hline 2003 & 1,535 & 1,503 \\
2004 & 1,632 & 1,657 \\
2005 & 1,725 & 1,811 \\
2006 & 1,906 & 1,966 \\
2007 & 2,136 & 2,120 \\
2008 & 2,314 & 2,274 \\
2009 & 2,438 & 2,428 \\
2010 & 2,708 & 2,582 \\
2011 & 2,871 & 2,737 \\
2012 & 2,880 & 2,891 \\
2013 & 2,917 & 3,045 \\
2014 & 3,152 & 3,199 \\
2015 & & 3,353 \\
2016 & & 3,508 \\
2017 & & 3,662 \\
2018 & & 3,816 \\
2019 & & 3,970 \\
2020 & & 4,125 \\
2021 & & 4,279 \\
2022 & & 4,433 \\
2023 & & 4,587 \\
2024 & & 4,741 \\
2025 & & 4,896 \\
\hline
\end{tabular}

Table 3 illustrates the actual values of the maximum loads and the date of occurrence through the years 2009 till 2014. The prediction of the peak load is helping to measure progress in planning and management activities for future. The data used in this study were for several years of the demand loads in the Kingdom of Bahrain. The models obtained are simple in term of equation used to calculate the estimated peak loads. 
Table 3 Actual peak load values and date of occurrence.

\begin{tabular}{lll}
\hline Year & Date & Load (MW) \\
\hline 2009 & 24-Aug.-09 & 2,438 \\
2010 & 25-Aug.-10 & 2,708 \\
2011 & 7-Aug.-11 & 2,812 \\
2012 & 23-Jul.-12 & 2,880 \\
2013 & 4-Sep.-13 & 2,917 \\
2014 & 21-Aug.-14 & 3,077 \\
\hline
\end{tabular}

\section{Annual Number of Population Modeling}

It is important to obtain the population of Kingdom of Bahrain based on the actual values for the period 2003-2014. For this purpose, it is necessarily to find the suitable package for that aim which is Graph 4.4.2. The package helps to find the most suitable model for the available population data. The obtained model helps to find the estimated values of the population through the period 2003 till 2025.

Eq. (3) shows the variation of population model (exponential model) for Kingdom of Bahrain through the years (2003-2014). The results coming out of the derived estimated population values equation for the period 2003-2025 are shown in the present article. These results are shown in Fig. 4 and listed in Table 4. The same data modeled as a linear model, where Eq. (4) represents the growth variation of population and estimated that, number of population for the period 2003-2025 using the linear model. These results are illustrated in Fig. 5 and listed in Table 5.

$$
\text { population }(x)=\left(5.2979177 \times 10^{-37}\right) \times 1.0496942^{x}
$$$$
\text { population }(x)=(50,242.864 x)-99,828,751
$$

where:

population $(x)$ : the estimated population as a function of year $(x)$ :

$$
x \text { : the year. }
$$

In the present article, it is presented the results which appear to be strong predicators of implementation progress. It is clear that, the model is used to in the present paper to predict the future population for two periods. The first period is the actual population statistics period (2003-2014), while the second period is the estimated population of
Kingdom of Bahrain period (2015-2025).

The prediction of the population is helping to measure progress in planning and management activities for future.

\section{Annual GDP Values Modeling}

The GDP is the primary indicator factor to measure the health of a country's economy. This indictor represents the total BD (Bahraini Dinars) value of

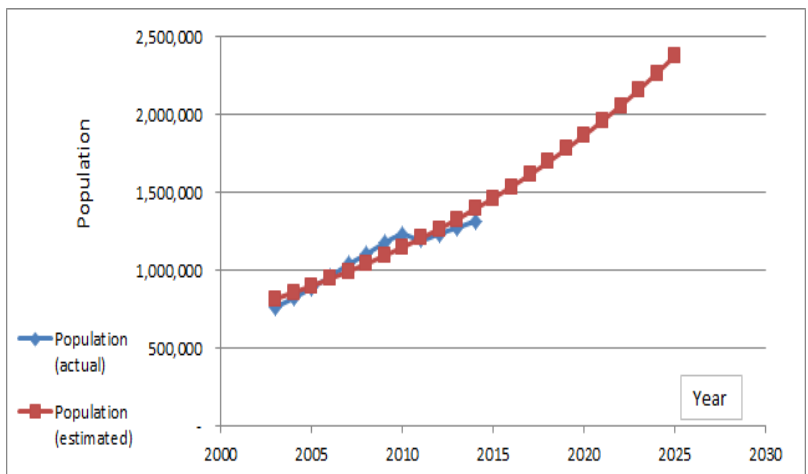

Fig. 4 Actual and estimated number of population for Kingdom of Bahrain using exponential model.

Table 4 Actual and estimated number of population using exponential modeling.

\begin{tabular}{lll}
\hline Year & Population (actual) & Population (estimated) \\
\hline 2003 & 764,519 & 818,255 \\
2004 & 823,744 & 858,918 \\
2005 & 888,824 & 901,601 \\
2006 & 960,425 & 946,405 \\
2007 & $1,039,297$ & 993,436 \\
2008 & $1,103,496$ & $1,042,804$ \\
2009 & $1,178,415$ & $1,094,625$ \\
2010 & $1,228,543$ & $1,149,022$ \\
2011 & $1,195,020$ & $1,206,122$ \\
2012 & $1,234,900$ & $1,266,059$ \\
2013 & $1,274,800$ & $1,328,975$ \\
2014 & $1,316,500$ & $1,395,017$ \\
2015 & & $1,464,341$ \\
2016 & & $1,537,110$ \\
2017 & & $1,613,496$ \\
2018 & & $1,693,677$ \\
2019 & & $1,777,843$ \\
2020 & & $1,866,192$ \\
2021 & & $1,958,931$ \\
2022 & & $2,056,278$ \\
2023 & & $2,158,463$ \\
2024 & & $2,265,726$ \\
2025 & & $2,378,320$ \\
\hline
\end{tabular}




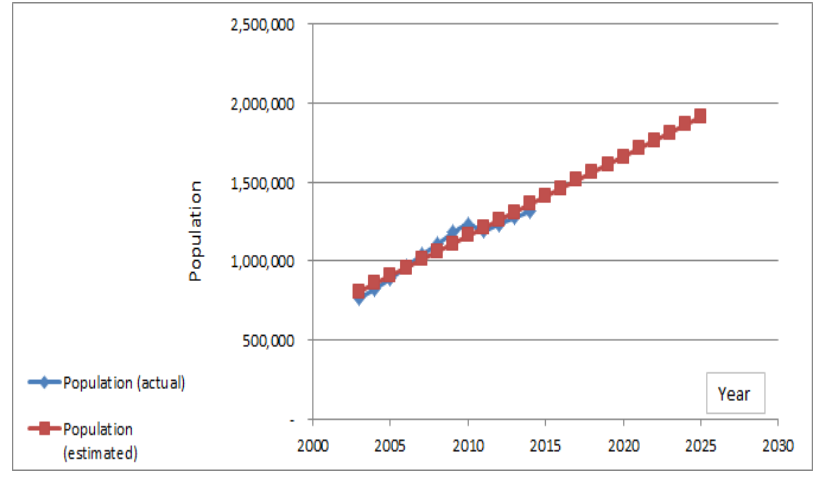

Fig. 5 Actual and estimated number of population for Kingdom of Bahrain using linear model.

Table 5 Actual and estimated number of population using linear modeling.

\begin{tabular}{lll}
\hline Year & Population (actual) & Population (estimated) \\
\hline 2003 & 764,519 & 807,706 \\
2004 & 823,744 & 857,948 \\
2005 & 888,824 & 908,191 \\
2006 & 960,425 & 958,434 \\
2007 & $1,039,297$ & $1,008,677$ \\
2008 & $1,103,496$ & $1,058,920$ \\
2009 & $1,178,415$ & $1,109,163$ \\
2010 & $1,228,543$ & $1,159,406$ \\
2011 & $1,195,020$ & $1,209,649$ \\
2012 & $1,234,900$ & $1,259,891$ \\
2013 & $1,274,800$ & $1,310,134$ \\
2014 & $1,316,500$ & $1,360,377$ \\
2015 & & $1,410,620$ \\
2016 & & $1,460,863$ \\
2017 & & $1,511,106$ \\
2018 & & $1,561,349$ \\
2019 & & $1,611,591$ \\
2020 & & $1,661,834$ \\
2021 & & $1,712,077$ \\
2022 & & $1,762,320$ \\
2023 & & $1,812,563$ \\
2024 & & $1,862,806$ \\
2025 & & $1,913,049$ \\
\hline
\end{tabular}

consumed electric power produced plus all goods and services over a specific period of time. This means this will measure the size of the economy of the country. The GDP expressed as a comparison to the previous quarter or year. Therefore, it is important to obtain the GDP of Kingdom of Bahrain based on the actual values for the period 2003-2014. For this purpose, a suitable technique for this aim needed is Graph 4.4.2. The technique helps to find the most suitable model for the available GDP data. The obtained model helps to find the estimated values of the GDP through the period 2003 till 2025.

Eq. (5) shows the variation of GDP model (exponential model) for Kingdom of Bahrain through the years (2003-2014). The results coming out of the derived estimated GDP values equation for the period 2003-2025 are shown in the present study. The results are shown in Fig. 6 and listed in Table 6. The same

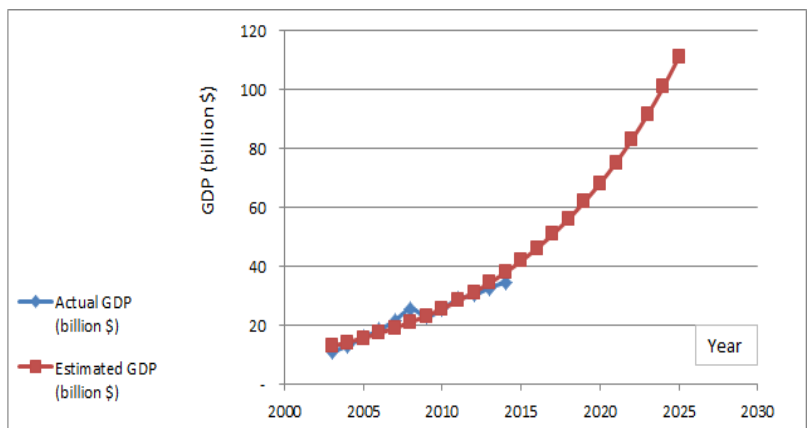

Fig. 6 Actual and estimated GDP values for Kingdom of Bahrain using exponential model.

Table 6 Actual and estimated GDP values using exponential modeling.

\begin{tabular}{lll}
\hline Year & $\begin{array}{l}\text { Actual GDP } \\
\text { (billion \$) }\end{array}$ & $\begin{array}{l}\text { Estimated GDP } \\
\text { (billion \$) }\end{array}$ \\
\hline 2003 & 11.08 & 12.97 \\
2004 & 13.15 & 14.30 \\
2005 & 15.97 & 15.77 \\
2006 & 18.51 & 17.38 \\
2007 & 21.73 & 19.17 \\
2008 & 25.71 & 21.14 \\
2009 & 22.94 & 23.30 \\
2010 & 25.71 & 25.70 \\
2011 & 29.04 & 28.33 \\
2012 & 30.36 & 31.24 \\
2013 & 32.79 & 34.45 \\
2014 & 34.78 & 37.99 \\
2015 & & 41.88 \\
2016 & & 46.18 \\
2017 & & 50.92 \\
2018 & & 56.15 \\
2019 & & 61.92 \\
2020 & & 68.27 \\
2021 & & 75.28 \\
2022 & & 83.01 \\
2023 & & 91.53 \\
2024 & & 100.92 \\
2025 & & 111.28 \\
\hline & &
\end{tabular}


data modeled as a linear model, where Eq. (6) represents the growth variation of GDP and estimated that GDP values for the period 2003-2025 using the linear model. These results are illustrated in Fig. 7 and listed in Table 7.

$$
\begin{gathered}
\operatorname{GDP}(x)=\left(1.3011731 \times 10^{-84}\right) \times\left(1.1026447^{x}\right) \\
\operatorname{GDP}(x)=(2.0979371 x)-4,190.2258
\end{gathered}
$$

where:

GDP $(x)$ : the estimated GDP value as a function of year $(x)$ :

$$
x \text { : the year. }
$$

In the present paper, it presents the results, which appear to be strong predicators of implementation progress. It is clear that, the model used in the present paper is to predict the future estimated GDP values for two periods. The first period is the actual GDP statistics period (2003-2014), while the second period is the estimated GDP of Kingdom of Bahrain period (2015-2025).

The prediction of the GDP is helping to measure progress in planning and management activities for future. The GDP represents the economic production and growth, which has a large impact on nearly everyone within that economy. A significant change in GDP usually has a significant effect on the stock market whether up or down.

\section{Minimum, Average and Maximum Percentages}

Earlier, the modeling of the annual maximum load, population and GDP carried out and obtained using the Graph 4.4.2. Both the exponential and linear models had obtained. As a summary of the results which shown earlier can be summarized in Tables 8 and 9 . Table 8 shows the results for the exponential modeling and Table 9 illustrates the results of the linear modeling. By comparing the results obtained and listed in both Tables 8 and 9, it is clear that, the percentage error for the three variables (population, peak load and GDP), is less in linear modeling than that of the exponential modeling, which means it was

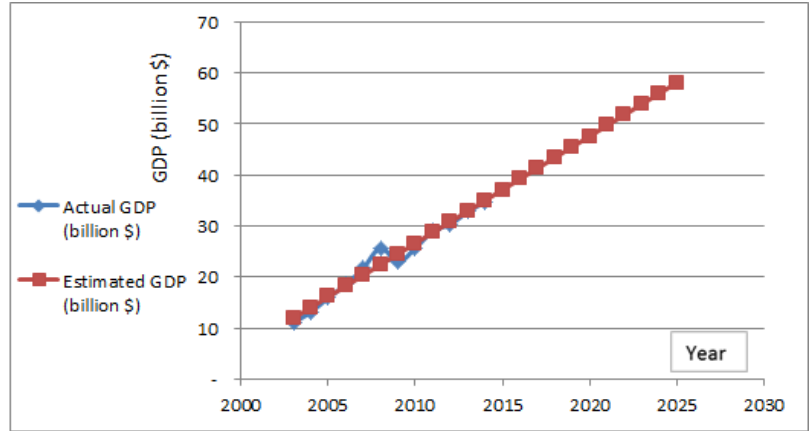

Fig. 7 Actual and estimated GDP values for Kingdom of Bahrain using linear model.

Table 7 Actual and estimated GDP values using linear modeling.

\begin{tabular}{lll}
\hline Year & $\begin{array}{l}\text { Actual GDP } \\
\text { (billion \$) }\end{array}$ & $\begin{array}{l}\text { Estimated GDP } \\
\text { (billion \$) }\end{array}$ \\
\hline 2003 & 11.08 & 11.94 \\
2004 & 13.15 & 14.04 \\
2005 & 15.97 & 16.14 \\
2006 & 18.51 & 18.24 \\
2007 & 21.73 & 20.33 \\
2008 & 25.71 & 22.43 \\
2009 & 22.94 & 24.53 \\
2010 & 25.71 & 26.63 \\
2011 & 29.04 & 28.73 \\
2012 & 30.36 & 30.82 \\
2013 & 32.79 & 32.92 \\
2014 & 34.78 & 35.02 \\
2015 & & 37.12 \\
2016 & & 39.22 \\
2017 & & 41.31 \\
2018 & & 43.41 \\
2019 & & 45.51 \\
2020 & & 47.61 \\
2021 & & 49.71 \\
2022 & & 51.80 \\
2023 & & 53.90 \\
2024 & & 56.00 \\
2025 & & 58.10 \\
\hline
\end{tabular}

Table 8 Minimum, average and maximum percentages using exponential modeling.

\begin{tabular}{lll}
\hline \multirow{3}{*}{ Population (\%) } & Minimum & 0.9 \\
& Average & 4.3 \\
& Maximum & 7.1 \\
\hline \multirow{3}{*}{ Peak load (\%) } & Minimum & 0.8 \\
& Average & 3.9 \\
& Maximum & 6.6 \\
\hline \multirow{3}{*}{ GDP (\%) } & Minimum & 1.3 \\
& Average & 7.0 \\
\hline
\end{tabular}


Table 9 Minimum, average and maximum percentages using linear modeling.

\begin{tabular}{lll}
\hline \multirow{3}{*}{ Population (\%) } & Minimum & 0.2 \\
& Average & 3.3 \\
& Maximum & 5.9 \\
\hline \multirow{3}{*}{ Peak Load (\%) } & Minimum & 0.4 \\
& Average & 2.5 \\
& Maximum & 4.7 \\
\hline \multirow{3}{*}{ GDP (\%) } & Minimum & 0.4 \\
& Average & 4.2 \\
\hline
\end{tabular}

more realistic. Therefore, it recommended following and using the linear modeling.

\section{Neuro-Fuzzy Technique}

The Neuro-Fuzzy systems are combination of advantages of the neural networks and fuzzy logic. It was noted that, neural networks have two main benefits. First, they are capable of learning non-linear mappings of numerical data. Second, they perform parallel computation. However, the operation of neural networks has also many weaknesses. Therefore, it is very hard to understand the meaning of weights, and the incorporation of prior knowledge into the system which is usually impossible. Fuzzy logic uses human understandable linguistic terms to express the knowledge of the system. This makes a possible close interaction between the system and human operator, which is a very desirable property.

Therefore, the aim of Neuro-Fuzzy systems is to combine collectively the benefits of both approaches. Simply, the operation of the system is expressed as linguistic fuzzy expressions and learning schemes of neural networks that used to learn the system. In addition, Neuro-Fuzzy systems allow incorporation of both numerical and linguistic data into the system. The Neuro-Fuzzy system is also capable of extracting fuzzy knowledge from numerical data.

The general model for the Neuro-Fuzzy system is shown in Fig. 8 which illustrates the five-layer connection for two inputs and one output. These five layers represent the Neuro-Fuzzy model, which is used to represent the population, GDP and years models are used to generate Bahrain peak load demand [12].

The operation of this system can be described layer by layer as follows:

- Layer 1: fuzzification

This layer consists of linguistic variables. Using membership functions of the linguistic variables $\mathrm{Ai}$ fuzzifies the crisp input $P_{\max }$.

Usually, triangular, trapezoid, or bell-shaped membership functions are used. For example, the bell-shaped membership functions are defined as follows:

$$
\mu_{c}(x)=\exp \left(\frac{\left\|x-c_{c}\right\|^{2}}{\sigma_{c}^{2}}\right)
$$

where, $x$ is a fuzzy set, $c_{c}$ is its center and $\sigma_{c}$ is its width.

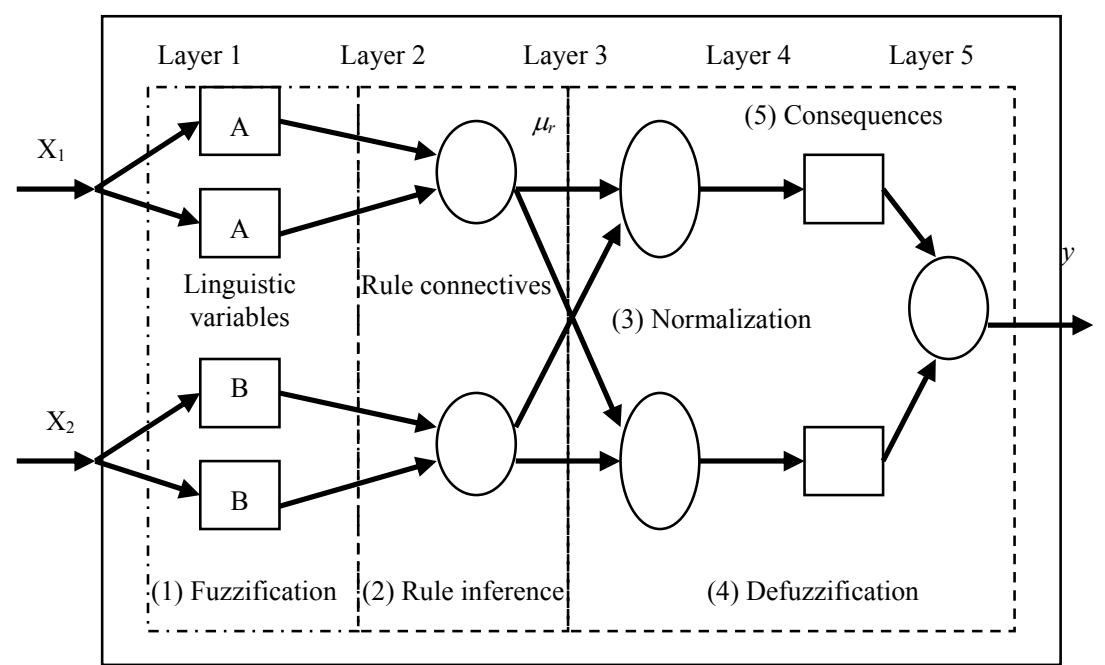

Fig. 8 A neural fuzzy inference system. 
- Layer 2: rule nodes

The second layer contains one node per each fuzzy if-then rule. Each rule node performs connective operation between rule antecedents (if-part). Usually, the minimum or the dot product is used as intersection AND. The union OR is usually done using maximum operation. In our example case the firing strengths $\alpha_{i}$ of the fuzzy rules are computed according to:

$$
\alpha_{i}=\min \left\{\mu_{A}\left(x_{1}\right), \mu_{B}\left(x_{2}\right)\right\}
$$

where, $\mu_{A}\left(x_{1}\right)$ and $\mu_{B}\left(x_{2}\right)$ are membership of input variables.

- Layer 3: normalization

In this layer, the firing strengths of the fuzzy rules are normalized according to:

$$
\alpha^{x}=\frac{\alpha_{r}}{\sum_{i=0}^{m} \alpha_{i}}
$$

- Layer 4: consequence layer

This layer is related to consequent fuzzy label $z_{i}$. The values of the singletons are multiplied by normalized firing strengths according to:

$$
f_{r}=\sum_{i=0}^{m} z_{i} \alpha^{x}
$$

- Layer 5: summation

This layer computes the overall output as the summation of the incoming signals:

$$
f_{s}=\sum_{i=0}^{m} f_{r}
$$

Newton algorithm is the popular truncated approach to find a step size and direction in weight space that drives a cost function towards its minimum. Using Taylor's expansion the cost function $J_{N}(\mathrm{w})$ can be locally approximated by the quadratic function Jang, et al. [12]:

$$
J_{N}(w+\Delta w)=J_{N}(w)+\Delta w \frac{\mathrm{d} J_{N}(w)}{\mathrm{d} w}+\frac{1}{2} \Delta w^{T} \frac{\mathrm{d}^{2} J_{N}(w)}{\mathrm{d} w^{2}} \Delta w
$$

where, $\Delta w$ is the weight vector update.

The new Neuro-Fuzzy weight update vector can be found by minimization of Eq. (13). Differentiating that function with respect to $w$, and setting the result to zero will minimize Eq. (13):

$$
\begin{gathered}
\frac{\mathrm{d} J_{N}(w)}{\mathrm{d} w}=\frac{\mathrm{d}^{2} J_{N}(w)}{\mathrm{d} w^{2}} \Delta w \\
g=-H \Delta w
\end{gathered}
$$

where, $g$ and $H$ represent the gradient and Hessian of $J_{N}\left(w_{k}\right)$, respectively.

The fuzzy reasoning rules can be divided into four main types. For simplicity, only the two-input single-output model of the Neuro-Fuzzy system is now presented. Four types of the fuzzy rules can be described as follows:

$$
\begin{gathered}
\text { IF } x_{1} \text { is } A_{1} \text { AND } x_{2} \text { is } A_{2} \text { THEN } y \text { is } B \\
\text { IF } x_{1} \text { is } A_{1} \text { AND } x_{2} \text { is } A_{2} \text { THEN } y \text { is } z \\
\text { IF } x_{1} \text { is } A_{1} \text { AND } x_{2} \text { is } A_{2} \text { THEN } y \text { is } f\left(x_{1}, x_{2}\right) \\
\text { IF } x_{1} \text { is } a_{j, 1} \text { AND } x_{2} \text { is } a_{j, 2} \text { THEN } y \text { is } z
\end{gathered}
$$

where, $x_{i}$ is the $i$-th input variable, and $A_{i}$ is the one of the linguistic variables defined for it.

The fuzzy output variable $y$ defined separately for each rule. In the first rule, the consequence of the rule is fuzzy set $B$, while the second rule uses a singleton. The consequence of third rule is a function of the input variable. The antecedent part of the fourth rule uses the reference values $a_{j, i}$, when the firing strength of the rule is computed by measuring the distance between the inputs and the references.

However, the operation of neural networks has also many weaknesses. For instance, in the popular multi-layer perception network the knowledge of the system distributed into the whole network as synaptic weights. Therefore, it is very hard to understand the meaning of weights, and the incorporation of prior knowledge into the system is usually impossible.

Fuzzy logic uses human understandable linguistic terms to express the knowledge of the system. This makes possible a close interaction between the system and human operator, which is very desirable property. Therefore, the aim of Neuro-Fuzzy systems is to combine collectively the benefits of both approaches. Simply, the operation of the system expressed as linguistic fuzzy expressions and learning schemes of neural networks used to learn the system.

In addition, Neuro-Fuzzy systems allow 
incorporation of both numerical and linguistic data into the system. The Neuro-Fuzzy system is also capable of extracting fuzzy knowledge from numerical data. The Neuro-Fuzzy systems divided into two main groups, the neural fuzzy inference systems and fuzzy neural networks. Learning the mapping of maximum power point data to inverter frequency leads to the formulation of an approximation problem.

Various neural networks, e.g., MLP (multi-layer perceptions) or radial-basis function networks are capable of learning nonlinear mappings and generalizing over a set of methods very accurately. Rule-based neural networks implement a fuzzy logic system.

The results coming out of the Neuro-Fuzzy are shown in Figs. 8-12. The obtained results have lowest percentage errors compared with previous two models (linear and exponential).

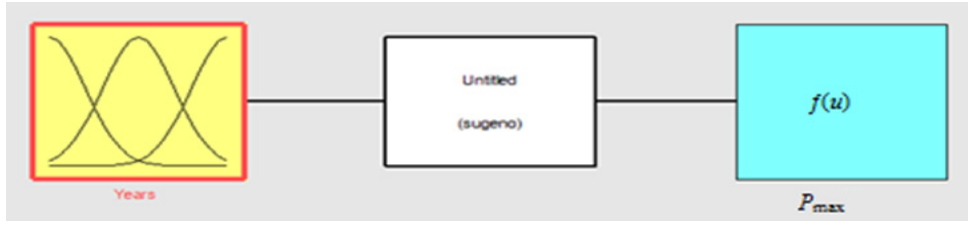

(a) Neuro-Fuzzy model using one input and one output

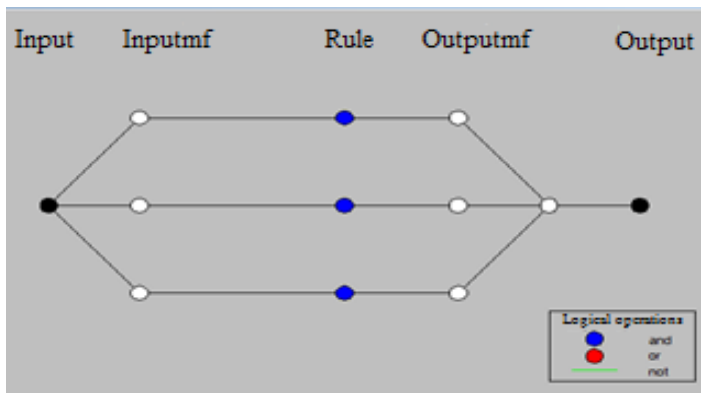

(b) The five stages in the Neuro-Fuzzy model
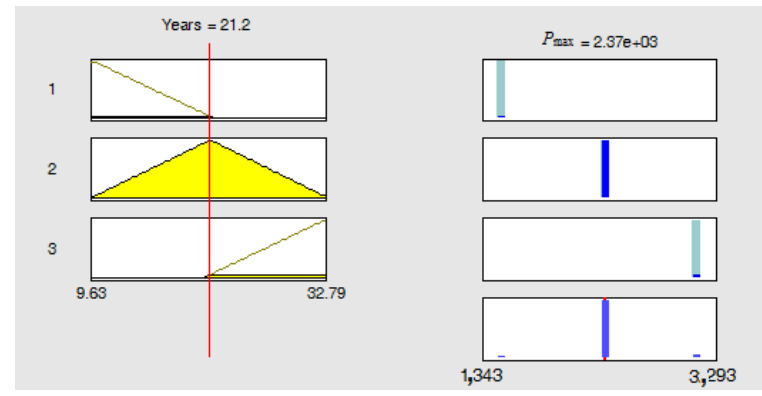

(c) Neuro-Fuzzy method to generate maximum peak load using membership function

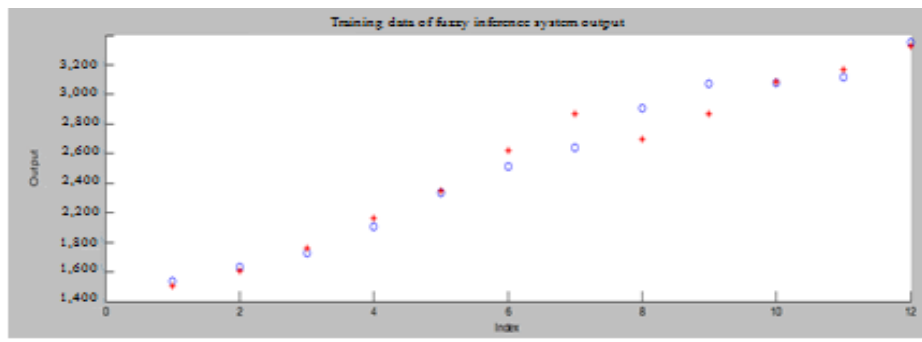

(d) Results of forecasted maximum peak load using Neuro-Fuzzy model vs. actual data where inputs is population and output is $P_{\max }$

Fig. 9 Neuro-Fuzzy maximum peak load model, stages, output calculation and results. 


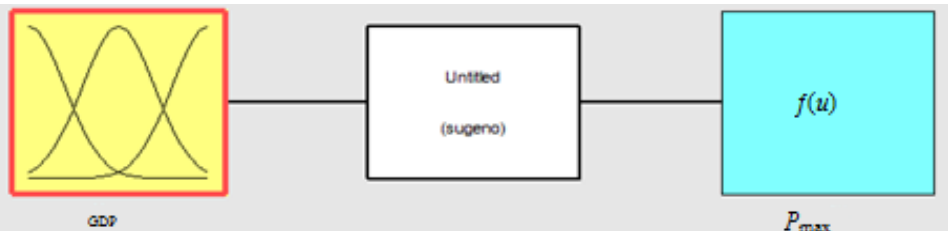

(a) GDP Neuro-Fuzzy model using one input and one output

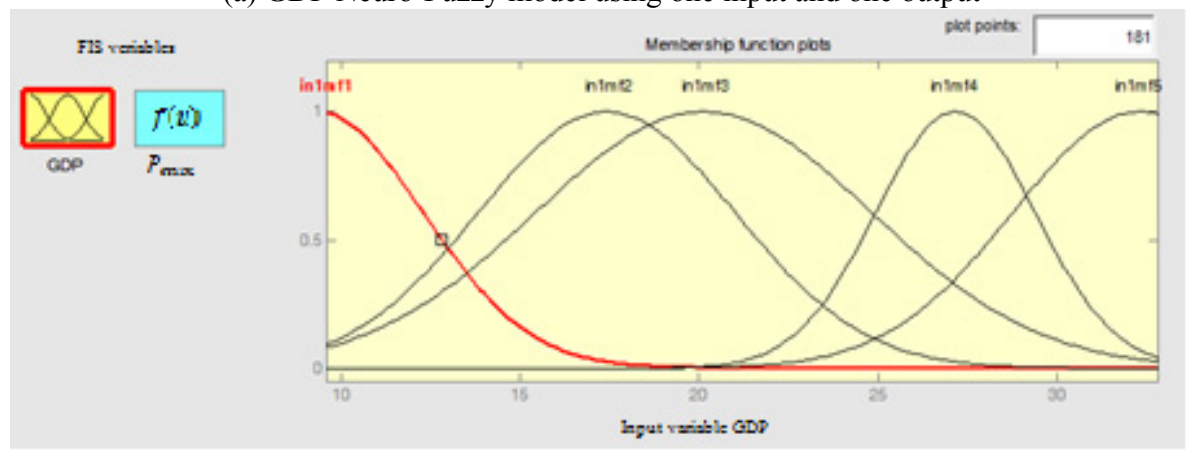

(b) GDP Neuro-Fuzzy membership used in the model
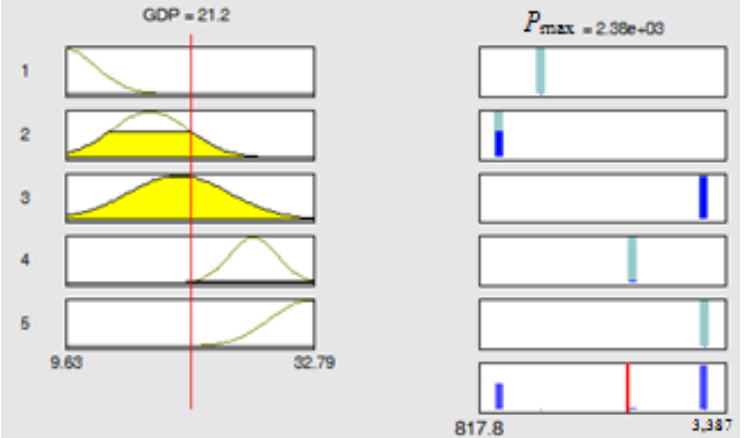

(c) Neuro-Fuzzy method to generate output value using membership function

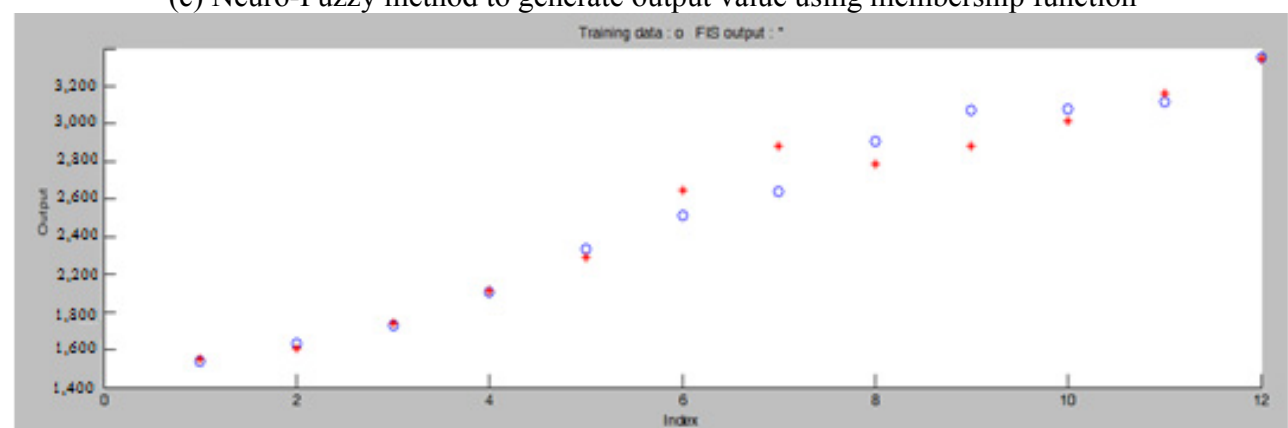

(d) Results of forecasted peak load using Neuro-Fuzzy model Vs actual data where inputs is GDP and output is $P_{\max }$

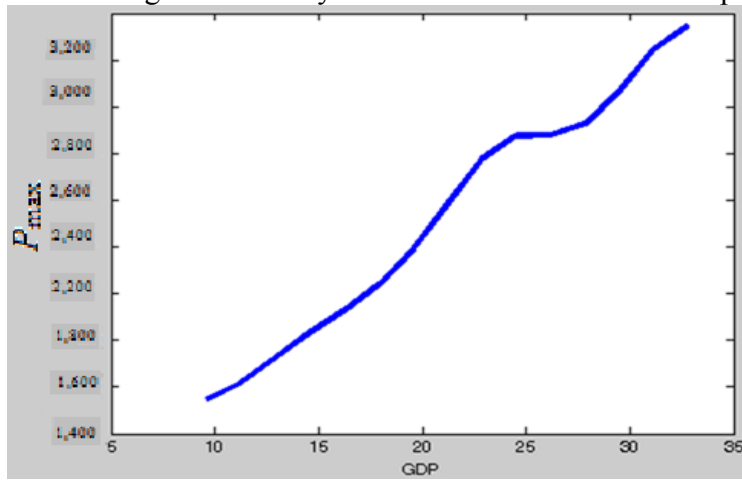

(e) Surface representation for the knowledged learned using adaptive neuro fuzzy inference system to represent the relation between GDP and $P_{\max }$

Fig. 10 GDP Neuro-Fuzzy model, stages, output calculation and results. 


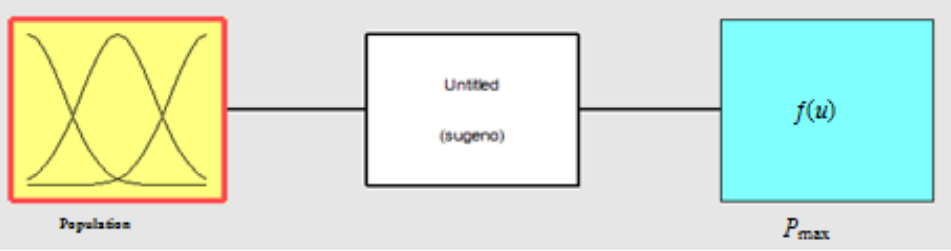

(a) Population Neuro-Fuzzy model to find $P_{\max }$ using one input and one output

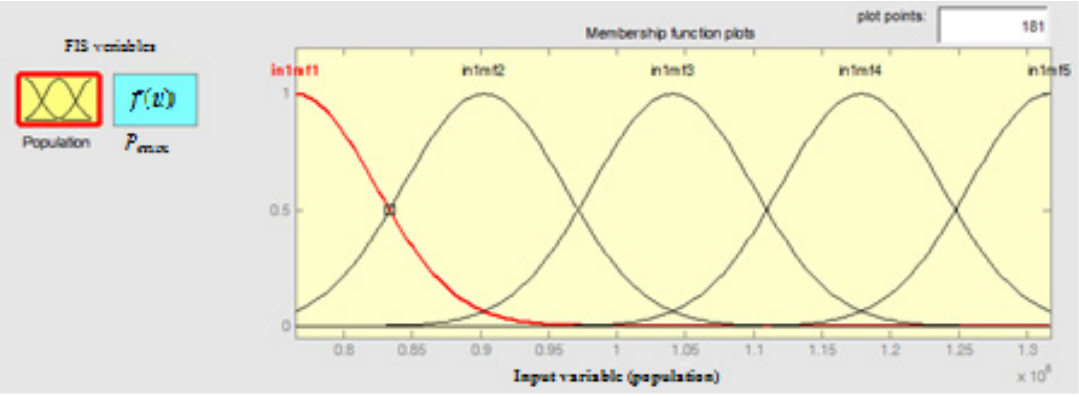

(b) Population Neuro-Fuzzy membership used in the model
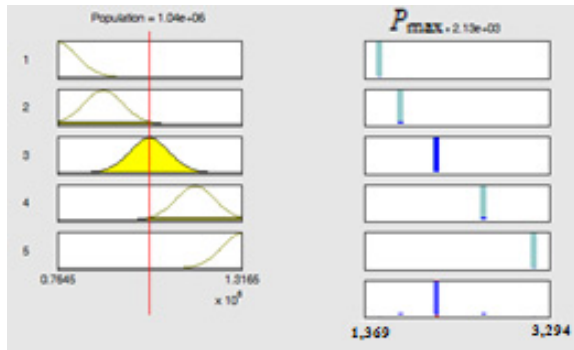

(c) Population Neuro-Fuzzy method to generate output value using membership function

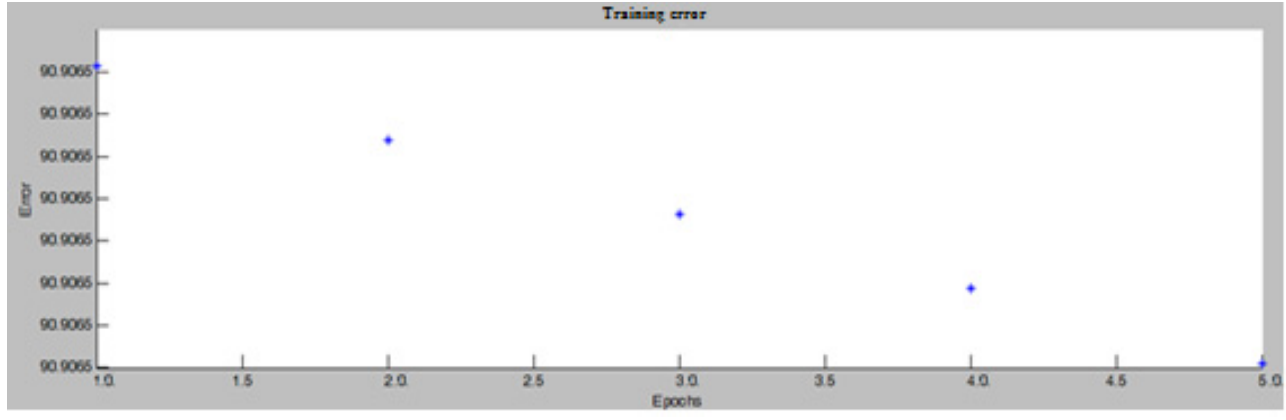

(d) Error (\%) for maximum peak load generated from the Population model using Neuro-Fuzzy model

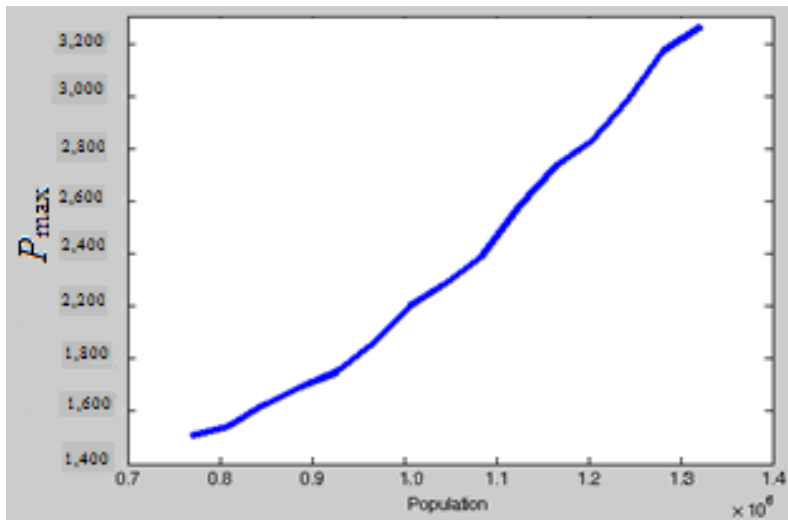

(e) Surface representation for the knowledged learned using ANFIS to represent the relation between Population and $P_{\max }$

Fig. 11 Neuro-Fuzzy model, stages, output calculation and result errors. 


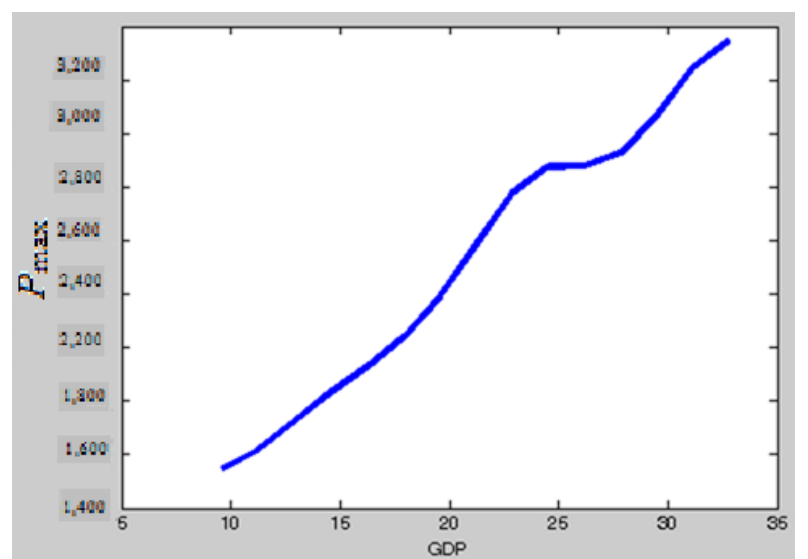

Fig. 12 Surface representation for the knowledged learned using adaptive Neuro Fuzzy inference system to represent the relation between GDP and $\boldsymbol{P}_{\max }$.

\section{Discussion}

It is necessary to investigate the properties of electricity maximum loads for the Kingdom of Bahrain. The yearly energy consumption at Bahrain during summer is increasing in the rate of $6 \%$ averagely, where it increases in certain years due to development in the country. The electricity demands increased instantaneously with time. Electricity is used for various purposes. It consumed at residential, industrial, agricultural and commercial sectors. Limited research studies on maximum load estimation of Bahrain reveal more exploration and investigation regarding theoretical and experimental framework. The historical data of the maximum loads of the Kingdom of Bahrain are illustrated in the previous sections. Bahrain network is connected to the GCC (Gulf Cooperation Council) countries (regional electric grid). Rising electricity demand indicates from the available data. The derived models can estimate the peak loads for the coming years. The models are used by anyone with a basic understanding of electric sector or even with no basic understanding. The moderate growth in the peak load is attributed to moderate economic growth over the time period of study which impacted both energy and peak load demand.

\section{Conclusions}

Two techniques are used in the present study to estimate the maximum loads, population and GDP for
Kingdom of Bahrain. These techniques are the exponential and linear modeling using Graph 4.4.2 as a curve fitting technique. The most suitable one and more realistic in modeling for the study is the linear modeling, where the minimum percentage error between the estimated and actual values is obtained. For the Population the maximum percentage error is $5.9 \%$ using the linear modeling, which shows for the exponential as $7.1 \%$. For the peak load, the maximum percentage error is $4.7 \%$ using the linear modeling, which shows for the exponential as $6.6 \%$. For the GDP, the maximum percentage error is $12.8 \%$ using the linear modeling, which shows for the exponential as $17.8 \%$. The Neuro-Fuzzy results are obtained having $1.15 \%$ error for the peal load versus years, $1.07 \%$ error for the GDP versus peak load and $0.91 \%$ error for population versus peak load. The present paper discusses simple models for estimated peak loads and an efficient algorithm to calculate the model parameters of each case. It is clear that, the input parameters of each model are historical loads, GDP and population data on the Kingdom of Bahrain. Finally, using most suitable modeling for the three estimated models, which are the annual peak load, population and GDP are found. These models are so close to the real values.

\section{Acknowledgments}

We would like to express our thanks to H. E. Dr. 
Abdul-Husain Bin Ali Mirza the Minister of Energy (Kingdom of Bahrain) for his encouragement and supporting the development of energy research.

\section{References}

[1] Qader, M. M., and Qamber, I. 2010. "Long-Term Load Forecasting for the Kingdom of Bahrain Using Monte Carlo Method." JAAUBAS 9 (1): 21-31.

[2] Almeshaiei, E., and Soltan, H. 2011. "A Methodology for Electric Power Load Forecasting." Alexandria Engineering Journal 50 (2): 137-44.

[3] Qamber, I. S. 2012. "Peak Load Modeling for Kingdom of Bahrain." Journal of Software Engineering and Applications 5 (12B): 46-9.

[4] Tawalbeh, N., and El-Khazali, R. 2012. "Peak Load Evaluation Based on the Accumulated Annual Energy." In Proceedings of the 16th IEEE Mediterranean Electro-technical Conference on MELECON (Mediterranean Electro-technical Conference) 2012, 544-7.

[5] Qamber, I. S. 2013. "Estimation of the Maximum Annual Loads Modeling for Kingdom of Bahrain." Journal of Energy and Power Engineering 7 (October): 2006-11.

[6] Ryu, J. H., Hong, W. H., and Seo, Y. K. 2014. "A Study of the Analysis on the Properties of Electricity Peak Load of Large Hotel Building in Consideration of Energy
Efficiency." Advanced Science and Technology Letters 47 (2): 6-10.

[7] Koo, B., Lee, S., Kim, W., and Park, J. 2014. "Comparative Study of Short-Term Electric Load Forecasting." In Proceedings of the Fifth IEEE International Conference on Intelligent Systems, Modelling and Simulation, 463-7.

[8] Upshaw, C. R., Rhodes, J. D., and Webber, M. E. 2015. "Modeling Peak Load Reduction and Energy Consumption Enabled by an Integrated Thermal Energy and Water Storage System for Residential Air Conditioning Systems in Austin." Energy and Buildings 97 (15): 21-32.

[9] Kot, R., Rolak, M., and Malinowski, M. 2013. "Comparison of Maximum Peak Power Tracking Algorithms for a Small Wind Turbine." Mathematics and Computers in Simulation 91 (May): 29-40.

[10] Barzin, R., Chen, J., Yourng, B. R., and Farid, M. M. 2015. "Peak Load Shifting with Energy Sorage and Price-Based Control System." Energy (article in press): $1-10$.

[11] Afua, M., and Mohamed, T. K. 2009. "A Review of Electrical Energy Management Techniques: Supply and Consumer Side (Industries)." Journal of Energy in Southern Africa 20 (3): 14-21.

[12] Gupta, M. M., and Rao, D. H. 1994. "On the Principles of Fuzzy Neural Networks.” Fuzzy Sets and Systems 61 (1): 1-18. 